tion of about $\frac{3}{4}$ million there are some 34 school clinic sessions per week, and the hospitals, already full, just could not fit in the extra sessions. Fortunately all but four of these clinics are run by S.H.M.O.s or the equivalent who have also assistant sessions at the regional eye unit and our six subsidiary hospitals, so that an adequate relationship of the two services is obtained.am, etc.,

Romford, Essex

John Primrose

\section{Practice in the United States}

SIR,-I am a British paediatrician in the United States on a one year fellowship. Before he comes to the United States a hospital doctor needs the E.C.F.M.G. certificate. He may then be under the impression that no further qualifications are necessary during the course of a one-year stay here.

Many doctors in the past have discovered on arrival in America that they cannot survive on their fellowship remuneration alone and have wanted to indulge in the universal and lucrative practice of "moonlighting." But unless the doctor arrives in the U.S. as a permanent immigrant, as opposed to an exchange visitor, he is precluded from taking the new examination known as F.I.E.X. (Federal Licensing Examination), which is essential if he is to indulge in work outside his own hospital. I wish to bring to the notice of my colleagues the limitations of coming as an exchange visitor and my realization that the E.C.F.M.G. qualification gives one only minimal rights.-I am, etc.

Donald Bentley

The Children's Hospital Medical Centre,
Boston, Massachusetts

\section{Outpatient Appointments System}

SIR,-Since the outpatient appointment system has been critically examined in various quarters my experience of it as a consultant physician might be of some interest. From early June 1971 to mid-July 1972 I kept a private record of all attendances of new patients at my general medical clinic. This amounted to 50 working weeks, four being taken as holiday and three omitted because of poor travelling conditions for patients.

I have used my appointment system continuously for five years. The clinic begins at 8.30 a.m., when follow-up patients are seen. Appointments for new patients, who are seen by myself, are made for the following times: 9.20 a.m. (two patients), 10 a.m., 10.15 a.m., 10.30 a.m., and 10.45 a.m. Afternoon appointments are made for 1.30 p.m. (two patients), 2.15 p.m., 2.30 p.m., 2.45 p.m., 3.15 p.m., 3.30 p.m., and 3.45 p.m. The clinics are always finished by 11.30 a.m. and 4.30 p.m. at the latest. In practice this system allows for 20 minutes per new case. There is no significant waiting list. A patient failing to attend is no sent a second appointment, but the patient's general practitioner is asked to instruct the patient to apply for a further appointment if this is considered necessary.

Cancellations of appointments 24 hours or more before the appointed time are not recorded as failures to attend. Cancellations within 24 hours are counted as failures unless the vacant period was used by another patient. All 50 morning clinics were full with one exception, when there were only three appointments. Seven afternoon clinics were not required and a further seven only partially filled, mainly round Christmas, Easter, and in August. There were appointments for 297 patients, and of these 11 failed to attend. The appointment of six of the 11 was for 9.20 a.m. Fourteen patients were between 10 to 25 minutes late for their appointment, 12 between 25-40 minutes late, and three over 40 minutes late; lateness was commonest at the early hour. There were 315 afternoon appointments made : 19 patients failed to attend, eight were $10-25$ minutes late, and two over 25 minutes late. Any lateness of less than 10 minutes was recorded as being on time. The reasons for lateness were not analysed in detail, but in about one quarter of the cases the delay was due to the ambulance service. This is not a criticism. The ambulance service has made every effort to co-operate. Rather it shows the problems of integrating an individual clinic with ambulance centres serving a group of hospitals and many clinics simultaneously. The remainder of the patients' reasons varied. A not uncommon statement to the sister was one of flusterid surprise that there was not to be the usual hour's waiting time.

In summary, 612 appointments were made, 30 were not kept, and 39 patients arrived ate enough to cause dislocation of the clinic. Thus in any list of nine appointments some waste of the consultant's or the patient's time can be expected. To try to avoid this I have taken the following steps: (1) No second appointments are made for non-attenders, except by request. (2) Two patients are allotted to the first appointment time in the morning and afternoon in the hope that one will be on time, but a slightly longer consultation period is allowed. (3) The appointment times are at 15-minute intervals, but a gap of $\mathbf{3 0}$ minutes is left in the middle of a longer clinic to allow for catching up if necessary. I conclude that a perfect system is impossible, but, equally, the waiting of many hours by patients or the wasting of many hours by consultants are both unnecessary.-I am, etc.,

St. Catherine's Hospital,

S. COPE

Birkenhead

\section{Toxicity of Benorylate}

SIR,-The request of Dr. R. E. HopeSimpson (3 February, p. 296) for information from other clinicians who might have had similar experiences to his own regarding the rapid onset of salicylism in patients receiving benorylate was met by a letter from Dr. K. Hingorani (17 February, p. 418), who expressed his confidence in benorylate as an antirheumatic drug. These letters prompt me to report the following observations.

Although tinnitus and some loss of hearing are to be expected in some patients when salicylates are administered at dosages intended to achieve an anti-inflammatory effect it has been my experience that the administration of benorylate at the recommended dosage of $4 \mathrm{~g}$ twice daily is associated with a greater frequency and earlier onset of symptoms of salicylism. In 20 patients with defined rheumatoid arthritis benorylate was administered as the sole antiinflammatory drug, and 11 patients developed severe tinnitus and deafness after the second dose of the suspension. Ten of these patients agreed to resume the compound at $2 \mathrm{~g}$ thrice daily after they had recovered from their symptoms, plasma salicylate levels being monitored three hours after each dose. However, nine of them developed similar symptoms after the third dose (mean time of onset after first dose, 18.2 hours) and were withdrawn from benorylate therapy. At the time of onset of tinnitus the mean total plasma salicylate concentration was $2.7 \pm 0.2$ (S.D.) $\mathrm{mmol} / 1$. Three days after cessation of all symptoms of salicylism the nine patients were given soluble aspirin at a dosage of $1.2 \mathrm{~g}$ four times a day and plasma salicylate concentrations were measured as previously. The mean total plasma salicylate concentration did not exceed $1.8 \pm 0.15 \mathrm{mmol} / \mathrm{l}$. at any time, and only one of the nine patients developed salicylism, which occurred on the fifth day of this regimen.

It has been demonstrated that at a total plasma salicylate level of $0.1 \mathrm{mmol} / 1$. approximately $1 \%$ of the drug is in the free form; this increases to $10 \%$ at $1 \mathrm{mmol} / 1$. and $25 \%$ at $3 \mathrm{mmol} / 1$. Toxicity rather than clinical effectiveness appears to be associated with the accumulation of unbound salicylate. Expected free salicylate concentrations, based on the total plasma levels measured, would give approximate values of 0.65 $\mathrm{mmol} / 1$. on benorylate and $0.15 \mathrm{mmol} / 1$. on aspirin. Whereas some human albumin molecules appear to possess fewer binding sites than others ${ }^{3}$ the present data suggest that this is unlikely to be a factor in the greater frequency and earlier onset of tinnitus and deafness with benorylate compared with equivalent dosages of aspirin. The abnarent half-time of salicvlate elimination following oral administration of aspirin is dose-dedendent, ${ }^{4}$ while benorvlate's rate of metabolism in man is slower than that of asoirin. ${ }^{5}$ It seems that there are susceptible individuals who experience tinnitus and deafness quite rapidly on the twice-daily dosage of benorylate but do not experience similar effects with equivalent dosage of aspirin. The study is being extended to evaluate the various mechanisms which reoulate plasma salicylate levels after the administration of benorylate in this group of patients.-I am, etc.,

MANSEL AYLWARD

Recearch Division

Merthyr Gereral Hospital, 1 Davison, C., and Smith, P. K., Fournal of 2 Smith, M. J. H., and Dawkins. P. D. Foumal of Pharmacy and Pharmarolooy, 1971. 23. 729.
Moran. C. I., and Walker. W. H. C., Biochemical Pharmacolony, 1968, 17. 153.

4 Levy, G and Lonerds, I ed. M. I. Smith and P. R. ' Smith. New York, Inter Science, 1966. 5 Robertson, A. VII Eurobean Rheumatology
Congress, 1971. Abstract No. 45/4.

Plasma Digoxin Concentration in Children with Heart Failure

SIR,-The paper by Dr. J. E. Cree and others (24 February, p. 443) is a useful contribution to the attempts being made to find a rational basis for the dosage regimen in children of varying ages.

However, the single estimations they made were of the plasma digoxin level after at least five days of maintenance therapy. This showed reasonable levels (in comparison with adult levels) on the maintenance regimen they followed. They do not, however, give any details of the blood levels achieved during the initial 24 hours of 